\title{
Qualidade da água de abastecimento de um abatedouro-frigorífico no município de
}

\section{Castanhal, Pará}

\author{
Quality of water supply for a slaughterhouse in the municipality of Castanhal, Pará \\ Calidad de suministro de agua para un matadero del municipio de Castanhal, Pará
}

Recebido: 06/02/2021 | Revisado: 11/02/2021 | Aceito: 16/02/2021 | Publicado: 24/02/2021

\author{
Andressa Souza Barboza \\ ORCID: https://orcid.org/0000-0002-9731-5329 \\ Universidade do Estado do Pará, Brasil \\ E-mail: Andressa.ss@ hotmail.com \\ Manoel Soares Damasceno Neto \\ ORCID: https://orcid.org/ 0000-0002-4605-3445 \\ Universidade Federal do Pará, Brasi \\ E-mail: manoel@veterinario.med.br \\ Welligton Conceição da Silva \\ ORCID: https://orcid.org/ 0000-0001-9287-0465 \\ Universidade Federal Rural do Pará, Brasil \\ E-mail: welligton.medvet@gmail.com \\ Bruna Emygdio Auriema \\ ORCID: https://orcid.org/0000-0002-6348-2209 \\ Universidade Federal Rural do Rio de Janeiro, Brasil \\ E-mail: bruna_bea@yahoo.com.br
}

\begin{abstract}
Resumo
A água de abastecimento é um recurso fundamental em abatedouros frigoríficos que fazem uso da água em diversas operações, seja de contato direto ou indireto com os produtos. Este estudo teve como objetivo avaliar os parâmetros de qualidade da água de abastecimento de um abatedouro frigorífico de bovinos, localizado no município de Castanhal, no estado do Pará. Para isto, as amostras de água foram coletadas em três diferentes pontos, sendo obtido amostras no setor de abate, miúdos e triparia. Realizou-se avaliação das características físico-químicas (cloro residual livre, cor aparente, $\mathrm{pH}$ e turbidez) e microbiológicos (coliformes totais e coliformes a $45^{\circ} \mathrm{C}$ ), durante o período de janeiro a dezembro de 2019. Os resultados mostraram que todos os parâmetros físico-químicos e microbiológicos das amostras analisadas mantiveram-se dentro dos padrões exigidos pelo Ministério da Saúde. Estes resultados podem ser reflexo do tratamento da água que o abatedouro emprega, que consiste nas etapas de correção do pH, floculação, coagulação, filtração e cloração.
\end{abstract}

Palavras-chave Potabilidade da água; Bovinos; Padrões microbiológicos; Cloro residual livre.

\begin{abstract}
Supply water is a fundamental resource in slaughterhouses that make use of water in various operations, whether in direct or indirect contact with the products. This study aimed to evaluate the quality parameters of the water supply for a slaughterhouse of bovine slaughterhouses, located in the municipality of Castanhal, in the state of Pará. For this, the water samples were collected in three different points, being obtained samples in the slaughtering, giblets and poultry sector. The physicochemical (free residual chlorine, apparent color, $\mathrm{pH}$ and turbidity) and microbiological (total coliforms and coliforms at $45^{\circ} \mathrm{C}$ ) characteristics were evaluated during the period from January to December 2019. The results showed that all physical-chemical and microbiological parameters of the analyzed samples remained within the standards required by the Ministry of Health. These results may reflect the water treatment that the slaughterhouse uses, which consists of the steps of $\mathrm{pH}$ correction, flocculation, coagulation, filtration and chlorination. Keywords: Potability of water; Cattle; Microbiological standards; Free residual chlorine.
\end{abstract}

\section{Resumen}

El suministro de agua es un recurso fundamental en los mataderos que utilizan el agua en diversas operaciones, ya sea en contacto directo o indirecto con los productos. Este estudio tuvo como objetivo evaluar los parámetros de calidad del suministro de agua para un matadero de mataderos de bovinos, ubicado en el municipio de Castanhal, en el estado de Pará. Para ello, las muestras de agua se recolectaron en tres puntos diferentes, obteniéndose muestras en el sacrificio, menudencias y sector avícola. Las características fisicoquímicas (cloro residual libre, color aparente, $\mathrm{pH}$ y turbidez) y microbiológicas (coliformes totales y coliformes a $45^{\circ} \mathrm{C}$ ) fueron evaluadas durante el período de enero a diciembre de 2019. Los resultados mostraron que todos los parámetros físico-químicos y microbiológicos de las muestras analizadas se mantuvieron dentro de los estándares exigidos por el Ministerio de Salud, estos resultados 
pueden reflejar el tratamiento de agua que utiliza el matadero, que consiste en las etapas de corrección de $\mathrm{pH}$, floculación, coagulación, filtración y cloración.

Palabras clave: Potabilidad del agua; Vacas; Estándares microbiológicos; Cloro residual libre.

\section{Introdução}

Indústrias processadoras de alimentos, principalmente do ramo frigorífico, utilizam elevada quantidade de água devido principalmente aos padrões sanitários de higiene das atividades que envolvem diversas etapas de lavagem, seja no processo de higienização dos produtos e ambiente quanto no resfriamento de compressores (Camargo, et al., 2016).

O uso da água (50 a 70\%) depende de práticas operacionais de limpeza, tais como processos de higienização, lavagem dos animais e produtos, na qual a evisceração e o processamento das vísceras correspondem a maior parte desse consumo (Nascimento, et al., 2011). Abatedouros frigoríficos de bovinos que abatem em média 500 animais/dia chegam a utilizar de 1000 a 3000 litros de água por animal (Souza, 2015).

A utilização de água imprópria nas indústrias de alimentos, seja pelo contato direto ou indireto, pode causar sérias consequências ao produto, causando impactos na qualidade dos alimentos e modificando suas características nutricionais e sensoriais. As impurezas contidas na água podem provocar alteração da cor e odor dos alimentos, aumento na turbidez de bebidas, além de representar risco a saúde do consumidor por infecções ou intoxicações alimentares (Wujie, et al., 2011).

Nos estabelecimentos que obtém e processam produtos de origem animal, o Memorando n ${ }^{\circ}$ 105/2018 do Ministério da Agricultura, Pecuária e Abastecimento (MAPA), estabelece a frequência e as formas de monitoramento da qualidade da água utilizada nas mais diversas etapas industrias, por meio de análises microbiológicas e análises físico-químicas básicas como cor, $\mathrm{pH}$, turbidez e cloro residual livre, realizadas in situ (no local) para verificação da potabilidade da água nas áreas de produção (Mapa, 2018).

A análise do cloro residual livre é do tipo colorimétrica utilizada para acompanhamento do processo de desinfecção da água, atuando sobre microrganismos patogênicos. Além de agente desinfetante, o cloro é utilizado na eliminação de odores e sabores da água, auxiliando também no combate a proliferação de algas e eliminação de matéria orgânica pela coagulação (MS, 2006).

O Ministério da Saúde determina a obrigatoriedade de se manter em qualquer ponto na rede de distribuição industrial da água a concentração mínima de cloro residual livre de $0,2 \mathrm{mg} / \mathrm{L}$ não sendo aceito como potável a água que apresentar menor concentração, uma vez que estará susceptível a contaminação microbiana (Anfarmag, 2013).

$\mathrm{Na}$ água também é possível encontrar minúsculas partículas com dimensões inferiores a $1 \mu \mathrm{m}$, denominadas coloides. Estas partículas possuem origem orgânica (ácidos húmicos e fúlvicos) ou mineral (resíduos industriais, compostos de ferro e manganês) que determinam a cor aparente da água (Piratoba, et al., 2017).

Além da cor, a turbidez da água também é um parâmetro importante e pode ser definido como a medida da dificuldade de um feixe de luz atravessar certa quantidade de água. Esta dificuldade tem origem devido a presença de materiais sólidos presentes na água e que se encontram em suspensão, como pela presença de algas, matéria orgânica, minerais como ferro, zinco e manganês, argilas e coloides (Correia, et al., 2008).

Do mesmo modo, o potencial hidrogeniônico $(\mathrm{pH})$ da água possui relevância quando relacionado a sua potabilidade. O Ministério da Saúde estabelece valores de pH entre 6,0 e 9,5 para água de abastecimento, uma vez que este intervalo minimiza problemas de incrustações e corrosão nas redes de abastecimento (MS, 2014).

As indústrias frigoríficas devem realizar o controle da qualidade da água utilizada, visando atender os critérios da regulamentação vigente, com periódicas avaliações das características microbiológicas e físico-químicas, de forma a contribuir com aspectos sanitários, econômicos e comerciais (Galletti, et al., 2010).

Tendo em vista a importâncias das características citadas, este estudo teve como objetivo avaliar os parâmetros da 
qualidade da água, de obrigatoriedade semanal segundo o Ministério da Agricultura Pecuária e Abastecimento, através de análises microbiológicas de coliformes totais e coliformes a $45{ }^{\circ} \mathrm{C}$ e análises físico-químicas de cloro residual livre, cor aparente, $\mathrm{pH}$ e turbidez, em um abatedouro frigorífico de bovinos localizado no estado do Pará, leste da região amazônica, durante o ano de 2019.

\section{Metodologia}

Respeitando o disposto pelo Ministério da Saúde no que tange os procedimentos de controle e vigilância da qualidade da água para consumo humano, as análises microbiológicas realizadas foram para a detecção da presença de coliformes totais e coliformes a $45^{\circ} \mathrm{C}$ (MS, 2017). As análises físico-químicas realizadas nas áreas de produção do estabelecimento incluíram os parâmetros de cor aparente, $\mathrm{pH}$, turbidez e cloro residual livre. O estudo realizado utilizou método quantitativo para coleta de dados uma vez que possibilita análise estatística dos dados (Pereira, et al, 2018).

\subsection{Local}

Este trabalho foi realizado em um abatedouro frigorífico de bovinos, de médio porte, que possui registro no Serviço de Inspeção Federal (SIF) do Ministério da Agricultura, Pecuária e Abastecimento, localizado no município de Castanhal, estado do Pará. O estabelecimento emprega 400 funcionários, trabalha em um turno de produção e possui autonomia para abater até 600 animais por dia. O estabelecimento realiza abate e desossa, além de expedir seus produtos para o mercado nacional e internacional.

\subsection{Coleta das amostras}

Os pontos de coleta de água foram escolhidos de acordo com os programas de autocontrole da empresa, de forma a abranger os setores produtivos que mais utilizam água no processo industrial, sendo estes as torneias das barreiras sanitárias dos setores de abate (ponto de coleta 1), miúdos (ponto de coleta 2) e triparia (ponto de coleta 3 ).

A coleta das amostras de água para análise microbiológica seguiu as orientações descritas no Manual de Coleta de Amostra de Produtos de Origem Animal do Ministério da Agricultura, Pecuária e Abastecimento (MAPA, 2020). Os procedimentos de coleta basearam-se na higienização da torneira com álcool 70\% e escoamento da água por aproximadamente 3 minutos, abertura da parte superior da bolsa de coleta estéril do tipo Whirl-Pak®, contendo tiossulfato de sódio, seguido da coleta da amostra.

A cada sete dias, durante o período de janeiro a dezembro de 2019, foram coletados $500 \mathrm{~mL}$ de água, aleatoriamente em um dos pontos de coleta descriminados, onde as bolsas de coleta foram inseridas em sacos plásticos, identificadas com o local e hora de coleta e devidamente acondicionadas em isopor com material refrigerante.

Para as análises físico-químicas, a coleta das amostras ocorreu pela inserção da água em frascos de vidro próprios de cada equipamento, na proporção de $10 \mathrm{~mL}$ para cada parâmetro, conforme as orientações do fabricante, realizada a cada sete dias nos três pontos de coleta.

\subsection{Análises microbiológicas}

As análises microbiológicas para pesquisa de coliformes totais e coliformes a $45{ }^{\circ} \mathrm{C}$ foram realizadas em laboratório terceirizado, portador de acreditação NBR ISO 9001, localizado na cidade de Belém - PA.

A metodologia utilizada para identificação de coliformes totais e coliformes a $45{ }^{\circ} \mathrm{C}$ foi o método tradicional de tubos múltiplos. O método dos tubos múltiplos é realizado em duas etapas: na primeira, a amostra é inoculada em caldo lauril sulfato de sódio, o qual inibe a microbiota acompanhante e, ao mesmo tempo é um meio de enriquecimento para bactérias do grupo 
dos coliformes. A presença de coliformes totais causam turvação no meio com formação de gás, detectado em tubos de Duhran, após 48 horas de incubação a $35 \pm 2{ }^{\circ} \mathrm{C}$. A segunda etapa é a confirmação da presença de coliformes a $45{ }^{\circ} \mathrm{C}$, através da inoculação de alçadas dos caldos lauril positivos em caldos seletivos para Escherichia coli (EC). Após incubação a $45 \pm 2$ ${ }^{\circ} \mathrm{C}$, durante 24 a 48 horas ocorre turvação do caldo EC com formação de gás, quando positivos para coliformes a $45{ }^{\circ} \mathrm{C}$ (Rompré, et al., 2002).

\subsection{Análises físico-químicas}

A aferição do cloro residual livre (CRL) foi realizada com auxílio do fotômetro (marca AKSO, modelo MW11) e reagentes hidróxido de sódio, ácido sulfúrico, sulfato de nitrogênio, N-dietil-1 e 4-fenilenodiamônio, através da lavagem e preenchimento da cubeta com a amostra, adição de 3 gotas de cada reagente, seguido da alteração da cor da amostra caso haja presença de cloro residual e leitura do equipamento para quantificação do resultado. $\mathrm{O} \mathrm{pH}$ foi determinado por meio do pHmêtro (modelo AK95) através da inserção do equipamento na amostra de água.

A medição da turbidez ocorreu pela avaliação de um turbidímetro (modelo TU430) e expresso em Unidade de Turbidez Nefelométrica (NTU). Para medição da cor da água utilizou-se o colorímetro (modelo AK530) e os resultados foram expressos em uH (Unidade Hazen - mgPt.L-1). Todos os equipamentos utilizados são da marca AKSO e, estavam devidamente calibrados e foram utilizados de acordo com as orientações do fabricante.

\subsection{Análise de dados}

Para análise microbiológica, realizou-se a cada sete dias análise em um dos 3 pontos de coleta, selecionados aleatoriamente. Os dados das análises físico-químicas foram analisados em triplicata, organizado em planilha do Microsoft Excel®, sendo expressos a média e o desvio padrão.

\section{Resultados e Discussão}

\subsection{Análise microbiológicas}

Os resultados das análises microbiológicas realizadas, mostraram que não foi possível observar, nos 3 pontos de coleta selecionados, durante o período de janeiro a dezembro de 2019, resultados positivos para coliformes totais e coliformes a 45 ${ }^{\circ} \mathrm{C}$, conforme observados na Tabela 1. 
Tabela 1. Resultados das análises microbiológicos das amostras de água de abastecimento no período de 2019.

\begin{tabular}{|c|c|c|c|}
\hline Meses & Ponto de coleta & Coliformes totais (UFC/mL) & $\begin{array}{c}\text { Coliformes a } 45^{\circ} \mathrm{C} \\
(\mathrm{NMP} / 100 \mathrm{~mL})\end{array}$ \\
\hline \multirow{3}{*}{ Janeiro } & 1 & Ausência & Ausência \\
\hline & 2 & Ausência & Ausência \\
\hline & 3 & Ausência & Ausência \\
\hline \multirow{3}{*}{ Fevereiro } & 1 & Ausência & Ausência \\
\hline & 2 & Ausência & Ausência \\
\hline & 3 & Ausência & Ausência \\
\hline \multirow{3}{*}{ Março } & 1 & Ausência & Ausência \\
\hline & 2 & Ausência & Ausência \\
\hline & 3 & Ausência & Ausência \\
\hline \multirow{3}{*}{ Abril } & 1 & Ausência & Ausência \\
\hline & 2 & Ausência & Ausência \\
\hline & 3 & Ausência & Ausência \\
\hline \multirow{3}{*}{ Maio } & 1 & Ausência & Ausência \\
\hline & 2 & Ausência & Ausência \\
\hline & 3 & Ausência & Ausência \\
\hline \multirow{3}{*}{ Junho } & 1 & Ausência & Ausência \\
\hline & 2 & Ausência & Ausência \\
\hline & 3 & Ausência & Ausência \\
\hline \multirow{3}{*}{ Julho } & 1 & Ausência & Ausência \\
\hline & 2 & Ausência & Ausência \\
\hline & 3 & Ausência & Ausência \\
\hline \multirow{3}{*}{ Agosto } & 1 & Ausência & Ausência \\
\hline & 2 & Ausência & Ausência \\
\hline & 3 & Ausência & Ausência \\
\hline \multirow{3}{*}{ Setembro } & 1 & Ausência & Ausência \\
\hline & 2 & Ausência & Ausência \\
\hline & 3 & Ausência & Ausência \\
\hline \multirow{3}{*}{ Outubro } & 1 & Ausência & Ausência \\
\hline & 2 & Ausência & Ausência \\
\hline & 3 & Ausência & Ausência \\
\hline \multirow{3}{*}{ Novembro } & 1 & Ausência & Ausência \\
\hline & 2 & Ausência & Ausência \\
\hline & 3 & Ausência & Ausência \\
\hline \multirow{3}{*}{ Dezembro } & 1 & Ausência & Ausência \\
\hline & 2 & Ausência & Ausência \\
\hline & 3 & Ausência & Ausência \\
\hline
\end{tabular}

Fonte: Autores (2021).

Os resultados apresentados demonstram que as amostram estavam em conformidade com o estipulado na Portaria de Consolidação $\mathrm{n}^{\circ}$ 5, de 28 de setembro de 2017 do Ministério da Saúde, que estabelece a ausência de coliformes totais e coliformes a $45{ }^{\circ} \mathrm{C}$ na água de abastecimento. Estes resultados podem ser decorrentes da eficácia da desinfecção realizada como parte do tratamento de água empregado na empresa, onde os níveis de cloro residual livre durante o período da pesquisa se mantiveram dentro dos limites estabelecidos pelo Ministério da Saúde (MS, 2017).

Outro fator que potencialmente influenciou nos resultados encontrados, deve-se a limpeza constante dos reservatórios e caixas d'água do abatedouro frigorífico, haja vista que o estabelecimento atende a Lei estadual $\mathrm{n}^{\circ} 5.882$ de 21 de dezembro de 1994 (Brasil, 1994). 
O Serviço de Inspeção Federal (SIF) do abatedouro frigorífico atende ao Memorando nº 105 de 10 de outubro de 2018 (MAPA, 2018), que estabelece a análise destes mesmos analitos a cada seis meses. Os resultados disponibilizados pelo SIF corroboram com os resultados obtidos nesta pesquisa, já que nas duas coletas realizadas pelo serviço de inspeção em 2019 não apresentaram resultados positivos para coliformes totais e coliformes a $45^{\circ} \mathrm{C}$.

Com resultados diferentes ao observados neste estudo, Barreto (2010) avaliou a água fornecida a unidades de alimentação de regiões administrativas do Distrito Federal pela pesquisa de coliformes totais e termotolerantes em 40 amostras e obteve resultado positivo, tanto para presença de coliformes a $35{ }^{\circ} \mathrm{C}$ e a $45{ }^{\circ} \mathrm{C}$ nas unidades de alimentação analisadas. Sendo, estes resultados justificados devido à baixa periodicidade de higienização dos reservatórios e problemas na tubulação de água.

O processo de desinfecção da água, geralmente utiliza compostos químicos com alto poder oxidante, que promovem a remoção de gosto e de cor, oxidação do ferro e manganês, além de melhorar o processo de coagulação e a eficiência da filtração, impede o crescimento de algas nos reservatórios e é responsável por impedir o crescimento dos microrganismos no sistema de distribuição (Oliveira, 2017).

O cloro como agente desinfetante terá sua eficiência alterada, pelas mudanças do $\mathrm{pH}$ do meio, da temperatura da água, da concentração de minerais oxidáveis e presença de matérias orgânicas. Sua ação ocorre especialmente, devido a seu poder oxidante, em particular, pela oxidação da glicose na célula bacteriana, bloqueando a ação da enzima triose-fosfóricodesidrogenase da membrana celular (Pardi, et al., 2005).

Porto et al. (2011), obtiveram resultados semelhantes a Barreto (2010) e divergentes ao do presente estudo, na qual avaliaram a qualidade microbiológica da água em 96 amostras e observaram que 11,46\% destas, estavam contaminadas por coliformes totais e 1,04\% apresentaram coliformes termotolerantes. Estes resultados foram associados a falhas no sistema de tratamento da água ou no momento da distribuição.

Da mesma forma, Rocha, et al. (2010), avaliaram a água de 36 instituições de ensino, cozinhas e cantinas, onde das 80 amostras analisadas, 2 apresentaram presença de coliformes totais e 5 apresentaram resultado positivo para coliformes termotolerantes, estando isto relacionado a falta de higienização dos reservatórios, manutenção das torneiras e tratamento da água utilizada.

\subsection{Análises físico-químicas}

Na Tabela 2 são expressos os valores médios encontrados nos três pontos de coleta, nos setores de Abate (1), Miúdos (2) e Triparia (3), para os parâmetros de cloro residual livre, cor aparente, turbidez e pH durante o período de janeiro a dezembro de 2019, onde observa-se que todos os valores obtidos encontravam-se dentro dos limites estabelecidos pelo Ministério da Saúde. 
Tabela 2. Médias e desvio padrão dos valores mensais de cloro residual livre, cor aparente, turbidez e pH da água de abastecimento durante o ano de 2019.

\begin{tabular}{|c|c|c|c|c|c|c|c|c|c|}
\hline \multirow[b]{2}{*}{ Meses } & \multirow[b]{2}{*}{$\begin{array}{l}\text { Ponto de } \\
\text { coleta }\end{array}$} & \multicolumn{8}{|c|}{ Parâmetros } \\
\hline & & $\begin{array}{c}\text { Cloro } \\
\text { Residual } \\
\text { Livre } \\
(\mathrm{mg} / \mathrm{L})\end{array}$ & $\begin{array}{l}\text { Desvio } \\
\text { padrão }\end{array}$ & $\begin{array}{c}\text { Cor } \\
\text { aparente } \\
(\mathbf{u H})\end{array}$ & $\begin{array}{l}\text { Desvio } \\
\text { padrão }\end{array}$ & $\begin{array}{c}\text { Turbidez } \\
\text { (NTU) }\end{array}$ & $\begin{array}{l}\text { Desvio } \\
\text { padrão }\end{array}$ & pH & $\begin{array}{c}\text { Desvio } \\
\text { padrão }\end{array}$ \\
\hline \multirow{3}{*}{ Janeiro } & 1 & 1,07 & 0,42 & 5,80 & 3,19 & 2,18 & 1,71 & 6,93 & 0,38 \\
\hline & 2 & 0,67 & 0,25 & 4,40 & 2,41 & 1,58 & 1,41 & 7,28 & 0,45 \\
\hline & 3 & 0,86 & 0,62 & 6,20 & 2,58 & 3,04 & 2,67 & 6,60 & 0,34 \\
\hline \multirow{3}{*}{ Fevereiro } & 1 & 0,88 & 0,25 & 5,50 & 2,51 & 2,05 & 0,61 & 7,19 & 0,45 \\
\hline & 2 & 0,93 & 0,23 & 4,25 & 3,20 & 1,76 & 0,93 & 7,12 & 0,29 \\
\hline & 3 & 1,35 & 0,51 & 4,25 & 1,70 & 1,56 & 0,55 & 7,17 & 0,18 \\
\hline \multirow{3}{*}{ Março } & 1 & 1,44 & 0,24 & 6,75 & 1,26 & 1,64 & 0,65 & 7,14 & 0,38 \\
\hline & 2 & 0,81 & 0,17 & 4,75 & 1,26 & 1,39 & 0,61 & 7,31 & 0,21 \\
\hline & 3 & 1,24 & 0,20 & 6,75 & 2,06 & 2,18 & 0,52 & 7,37 & 0,71 \\
\hline \multirow{3}{*}{ Abril } & 1 & 0,84 & 0,35 & 9 & 2,94 & 1,54 & 1,17 & 6,78 & 0,45 \\
\hline & 2 & 0,80 & 0,19 & 8,25 & 3,59 & 1,8 & 0,92 & 6,97 & 0,38 \\
\hline & 3 & 0,80 & 0,22 & 7 & 4,96 & 1,80 & 1,59 & 6,77 & 0,38 \\
\hline \multirow{3}{*}{ Maio } & 1 & 0,92 & 0,64 & 7,75 & 2,06 & 2,63 & 0,50 & 7,11 & 0,16 \\
\hline & 2 & 0,92 & 0,15 & 7,75 & 3,09 & 2,44 & 0,95 & 6,85 & 0,19 \\
\hline & 3 & 1,10 & 0,27 & 6 & 2,94 & 2,37 & 0,66 & 6,84 & 0,37 \\
\hline \multirow{3}{*}{ Junho } & 1 & 0,95 & 0,48 & 7,50 & 4,51 & 1,84 & 0,80 & 6,75 & 0,11 \\
\hline & 2 & 0,65 & 0,16 & 6,25 & 1,89 & 1,89 & 1,30 & 6,49 & 0,45 \\
\hline & 3 & 0,90 & 0,44 & 7,25 & 2,87 & 1,57 & 1,57 & 6,64 & 0,24 \\
\hline \multirow{3}{*}{ Julho } & 1 & 0,68 & 0,20 & 5,25 & 2,22 & 0,90 & 0,26 & 6,45 & 0,44 \\
\hline & 2 & 0,90 & 0,17 & 6 & 2,06 & 2,23 & 1,34 & 6,88 & 0,03 \\
\hline & 3 & 0,71 & 0,18 & 7 & 1,41 & 0,97 & 0,37 & 6,75 & 0,10 \\
\hline \multirow{3}{*}{ Agosto } & 1 & 0,90 & 0,29 & 5 & 2,31 & 1,92 & 0,84 & 6,74 & 0,14 \\
\hline & 2 & 0,90 & 0,31 & 6 & 3,56 & 2,23 & 0,50 & 6,88 & 0,09 \\
\hline & 3 & 0,84 & 0,02 & 6,75 & 2,06 & 1,80 & 0,22 & 6,62 & 0,22 \\
\hline \multirow{3}{*}{ Setembro } & 1 & 0,69 & 0,23 & 6,50 & 1,73 & 1,92 & 1,14 & 6,94 & 0,16 \\
\hline & 2 & 0,69 & 0,28 & 8,5 & 1,00 & 1,63 & 1,30 & 6,77 & 0,21 \\
\hline & 3 & 0,75 & 0,22 & 6,5 & 2,38 & 1,80 & 1,51 & 6,62 & 0,20 \\
\hline \multirow{3}{*}{ Outubro } & 1 & 0,83 & 0,19 & 7 & 1,87 & 3,58 & 0,98 & 6,70 & 0,32 \\
\hline & 2 & 0,78 & 0,14 & 8,6 & 1,67 & 2,74 & 1,60 & 6,64 & 0,32 \\
\hline & 3 & 0,95 & 0,19 & 6,80 & 3,27 & 2,38 & 0,51 & 6,57 & 0,36 \\
\hline \multirow{3}{*}{ Novembro } & 1 & 0,89 & 0,32 & 6,60 & 2,30 & 2,03 & 0,48 & 6,74 & 0,13 \\
\hline & 2 & 0,84 & 0,21 & 5,60 & 2,30 & 2,20 & 0,49 & 6,86 & 0,26 \\
\hline & 3 & 0,94 & 0,33 & 6,40 & 2,07 & 2,17 & 0,98 & 6,07 & 0,35 \\
\hline \multirow{3}{*}{ Dezembro } & 1 & 0,97 & 0,37 & 9,75 & 4,42 & 1,15 & 0,76 & 6,79 & 0,24 \\
\hline & 2 & 1,06 & 0,28 & 9,75 & 4,14 & 1,28 & 0,36 & 6,78 & 0,30 \\
\hline & 3 & 0,74 & 0,24 & 10,25 & 2,21 & 1,68 & 1,05 & 6,73 & 0,15 \\
\hline
\end{tabular}

Fonte: Autores (2021).

É possível observar, que durante o período da pesquisa, todos os valores encontrados se mantiveram dentro dos limites estabelecidos pela Portaria de Consolidação n 5, de 28 de setembro de 2017 do Ministério da Saúde. O Ministério da Saúde (2017), dispõe que a os valores máximos para cor aparente e turbidez, respectivamente sejam de 15 unidades Hazen (1 $\mathrm{uH}=1 \mathrm{mg}$ Pt-Co/L) e cinco unidades de Turbidez Nefelométrica (NTU).

Resultados semelhantes foram obtidos por Castro e Espontão (2010), que analisaram diversos parâmetros físicoquímicos da água de abastecimento industrial de um frigorífico em Minas Gerais, onde todas as análises durante três meses de pesquisa apresentaram valores em conformidade com os parâmetros permitidos pelo Ministério da Saúde.

Da mesma forma, em análise da água de abastecimento de 5 reservatórios de uma indústria de alimentos pequeno porte em Campina Grande - PR, Almeida e colaboradores (2020) não encontraram resultados com valores acima do estabelecido pela legislação para os parâmetros analisados.

Neste estudo, os resultados observados podem ser consequência da eficiência da Estação de Tratamento de Água (ETA) utilizada na empresa, haja vista que toda água superficial captada, antes de ser utiliza na indústria, passa pelas etapas de correção do pH, coagulação, floculação, decantação, filtração e desinfecção, respectivamente. 
Os resultados do desvio padrão empregado nos três pontos de coleta para todos os parâmetros analisados demonstram baixa dispersão para os resultados de cloro residual livre e pH uma vez que não apresentaram valores superiores a $1 \mathrm{mg} / \mathrm{L}$. Em contrapartida, a cor e a turbidez apresentaram grande dispersão haja vista a variância dos valores encontrados. Esta variação pode ser decorrente de problemas ocasionados pelas tubulações de água utilizadas entre os pontos, uma vez que não há padronização das tubulações utilizadas na distribuição da água na empresa, onde em setores diferentes, a empresa faz uso de diferentes tipos de material, como ferro, ferro galvanizado e aço inox.

Destaca-se também que a cor e a turbidez podem ser influenciadas pelo desgaste dos canos utilizados e com o uso prolongado, liberar rouge. Segundo Morellato (2002) o rouge é um fenômeno que acomete sistemas de tubulação pela formação de óxido de ferro coloidal, juntamente com traços de metais pesados como níquel e cromo. Sendo caracterizado pelo aparecimento, no interior das tubulações, de coloração levemente avermelhada ou marrom que pode progredir, em estágios extremos, a uma cor cinza ou preta.

No presente estudo, o parâmetro turbidez apresentou-se dentro dos valores de normalidade. Em contrapartida, Silva, et al. (2016) em análise da qualidade da água de abastecimento público do município de Jaboticabal - SP, observaram elevados valores de turbidez em diferentes pontos de coleta do manancial superficial que abastece a cidade. Estes valores sofreram significativa queda após passarem pelas etapas de tratamento da água, como floculação, decantação e filtração.

Outro fator que pode interferir na qualidade da água, são as chuvas, que de acordo com Freitas, et al. (2007) estas proporcionam um aumento da dispersão do material orgânico contido na água, além de carrear resíduos de outros locais, o que pode ocasionar o aumento dos valores de cor e turbidez da água. De acordo com Moraes, et al. (2005), a estação chuvosa da região nordeste do estado do Pará inicia-se em dezembro e finaliza em junho.

Pelos resultados obtidos, percebe-se um ligeiro aumento no valor da cor aparente da água nos três pontos de coleta nos meses de abril, maio, junho e dezembro. Neste período, os maiores valores de cor não sofreram influência da turbidez, uma vez que esta não apresentou aumento significativo nos referidos meses.

Piveli, et al. (2006) afirmam que águas em que a cor é elevada e a turbidez é baixa pode ser devido a presença de ferro, o que pode explicar os resultados observados neste período. Como forma de remover o excesso de ferro na água, a précloração auxiliaria neste processo, uma vez que a oxidação do ferro causada pelo cloro possibilitaria um aumento no tamanho das partículas de ferro, capazes de serem capturadas nas etapas de tratamento da água (Lima, 2019). Porém, a pré-cloração não é recomendada, uma vez que acarreta a formação de trihalometanos, devido a reação do cloro com material orgânico (Ghernaout \& Elboughdiri, 2020).

Freitas, et al. (2007), em análise da influência da qualidade da água no período chuvoso em um município do Ceará, afirmam que o período de chuvas influenciou diretamente nos valores de cor aparente e turbidez das amostras, onde estes resultados são explicados pela elevada concentração de ferro na água, devido ao processo de carreamento do solo no período de maior atividade pluviométrica.

Catuxo, et al. (2017) ao analisarem os aspectos físico-químicos da água de corpos hídricos situados na mesorregião de Castanhal - PA, observaram que 77\% da cidade é abastecida pelo rio Apeú e que durante as análises de cor aparente e turbidez apresentaram valores médio de 76 PtCo/L-1 e 10 NTU. Os valores encontrados são de análise da água bruta, sem tratamento de potabilidade. Os resultados observados corroboram para validação da eficiência do tratamento dispendido na empresa.

\section{Conclusão}

De acordo com o exposto, constata-se que o tratamento realizado pela empresa é eficiente e que consegue fornecer água de qualidade para uso industrial, de acordo com os parâmetros microbiológicos e físico-químicos analisados, uma vez que os valores obtidos das análises se encontram de acordo com a Portaria de Consolidação n ${ }^{\circ}$ 5, de 28 de setembro de 2017 do 
Ministério da Saúde.

Uma análise mais criteriosa da concentração de ferro, manganês e outro metais, assim como a análise de substâncias orgânicas e inorgânicas, como sólidos dissolvidos totais, para avaliação da influência na cor aparente e turbidez da água, segundo o Ministério da Saúde seria relevante para uma investigação aprofundada da qualidade da água utilizada pelo abatedouro, assim como a padronização das tubulações utilizadas nos diferentes pontos de distribuição de água, de modo a eliminar a possibilidade de diferenças significativas dos parâmetros físico-químicos entre os setores de produção.

\section{Agradecimentos}

Os autores agradecem ao abatedouro frigorífico, localizado na Cidade de Castanhal, Pará, por permitir a realização dessa pesquisa.

\section{Referências}

Anfarmag (Associação Nacional de Farmacêuticos Magistrais). (2013). Água potável: Monitoramento, controle de processo e ações corretivas. Revista Técnica do Farmacêutico. https://anfarmag.org.br/files/artigo-tecnico/20130725_092325_12069.pdf.

Almeida, R. L. J., Santos, N. C., Pereira, T. dos S., Silva, V. M. de A., Ribeiro, V. H. de A. Silva, L. R. I., Muniz, C. E. de S., Moreira, F. I. N., Pinheiro, W. S., \& Eduardo, R. S. Análise físico-química e microbiológica de reservatórios de água para abastecimento industrial. Research, Society and Development, 9(4). $10.33448 /$ rsd-v9i4.2795.

Pereira A. S., Shitsuka, D. M., Parreira, F. J., \& Shitsuka, R. (2018). Metodologia da pesquisa científica. UFSM. https://repositorio.ufsm.br/bitstream/handle/ /15824/Lic_Computacao_Metodologia-Pesquisa-Cientifica.pdf?sequence=1

Barreto, E. F. (2010). Análise microbiológica da água fornecida a unidades de alimentação de regiões administrativas do Distrito Federal. Anuário da Produção de Iniciação Científica Discente, XII(13).

Brasil, Estado do Pará. (1994). Lei $n^{\circ} 5.882$ de 21 de dezembro de 1994: institui a obrigatoriedade da higienização e desinfecção dos reservatórios prediais de água destinada ao consumo humano. Pará.

Castro, A. M., \& Espontão, R. T. (2010). Avaliação dos parâmetros físico-químicos da água de abastecimento industrial de um frigorífico do Triângulo Mineiro. PUBVET - Publicações em Medicina Veterinária e Zootecnia, Londrina, 4(18).

Camargo, J. A., Henkes, J. A., \& Rossato, I. F. (2016). Avaliação do consumo de água em abatedouro de aves visando a redução e ou reutilização de água. Revista Gestão \& Sustentabilidade Ambiental, 5(2), 675-693. http://dx..org/10.19177/rgsa.v5e22016675-693.

Catuxo, V. T. S., Sousa, P. H. C., \& Silva, M. C. N. C. (2017). Avaliação de aspectos físico-químicos da água de cinco corpos hídricos situados na microrregião da cidade de Castanhal-PA. Congresso Técnico Científico da Engenharia e da Agronomia. 1. Belém.

Correia, A., Barros, E., Silva, J., Ramalho, J. (2008). Análise da turbidez da água em diferentes estados de tratamento. In: $8^{\circ}$ Encontro Regional de Matemática Aplicada e Computacional. Universidade federal do Rio Grande do Norte, Natal.

Freitas, C. A. E., Nogueira, A. S., Lima, J. A. F., Lacerda, L. K. V., \& Gondim, A. L. N. (2007). Influência do período chuvoso na qualidade da água do açude do meio no estado do Ceará. $47^{\circ}$ Congresso Brasileiro de Química, Natal.

Galletti, J. P., Floresta, A. C. F., \& Santos, H. D. (2010). Qualidade da água de abastecimento na indústria de produtos de origem animal: revisão bibliográfica. Enciclopédia Biosfera, 6(10).

Ghernaout, D., \& Elboughdiri, N. (2020). Disinfection By-Products: presence and elimination in drinking water. Open Access Library Journal, 7:6140.

Lima, J. K. L. (2019). Avaliação da filtração direta descendente no tratamento de água de manancial com baixa turbidez e cor elevada. 2019. 74p. [Dissertação]. Instituto Federal de Educação, Ciência e Tecnologia do Rio Grande do Norte, Programa de Pós-graduação em Ciências Ambientais, Natal.

MAPA (Ministério da Agricultura, Pecuária e Abastecimento). (2020). Manual de coleta de amostras de produtos de origem animal. Brasília.

MAPA (Ministério da Agricultura, Pecuária e Abastecimento). (2018). Memorando $n^{\circ}$ 105/2018/CRISC/CGPE/DIPOA/SDA/MAPA. Brasília.

Ministério da Saúde (MS). (2017). Portaria de Consolidação $n^{\circ} 05$, de 28 de setembro de 2017. Brasília.

Ministério da Saúde (MS). (2006). Vigilância e Controle da Qualidade da Água para consumo humano. Brasília.

Moraes, B. C., Costa, J. M. N., \& Costa, A. C. L. (2005). Variação espacial e temporal da precipitação no estado do Pará. Acta Amazônica, $35(2)$ :207-214.

Morellato, F. Mecanismos de formação do rouge. (2002). https://www.grupohumma.com.br/biblioteca/rouge.pdf.

Nascimento, T. P. A., Santo, M. L., Santos, V. O., Castro, W. S., \& Santos, J. A. (2011). Tratamento e reaproveitamento de efluentes provenientes da dessentação de animais em frigoríficos e abatedouros de pequeno porte. II Congresso Brasileiro de Gestão Ambiental, Paraná. 
Research, Society and Development, v. 10, n. 2, e47510212729, 2021

(CC BY 4.0) | ISSN 2525-3409 | DOI: http://dx.doi.org/10.33448/rsd-v10i2.12729

Oliveira, R. R. (2017). Estudo do potencial de formação de trihalometanos na água da lagoa de Extremoz - RN. 2017. 73p. [Dissertação]. Instituto Federal de Educação, Ciência e Tecnologia do Rio Grande do Norte, Programa de Pós-graduação em Ciências Ambientais, Natal.

Pacheco, J. W. (2008). Guia técnico ambiental de abates (bovinos e suínos). CETESB - Companhia de Tecnologia de Saneamento Ambiental.

Pardi, M. C. (2005). Ciência, higiene e tecnologia da carne. (2a ed.), Editora da FGV.

Piratoba, A. R. A., Ribeiro, H. M. C., \& Morales, G. P. (2017). Caracterização de parâmetros de qualidade da água na área portuária de Barcarena, PA, Brasil. Revista Ambiente \& Água, 12(3).

Piveli, R. P., \& Kato, M. T. (2006). Qualidade das águas e poluição: aspectos físico-químicos. [S.1: s.n.], 2006. : https://repositorio.usp.br/item/001550353.

Porto, M. A. L., Oliveira, A. M., \& Fai, A. E. C. (2011). Coliformes em água de abastecimento de lojas fast-food da Região Metropolitana de Recife (PE, Brasil). Ciência \& Saúde coletiva, Rio de Janeiro, 16(5):2653-2658.

Rocha, E. S., Rosico, F. S., \& Silva, F. L. (2010). Análise microbiológica da água de cozinhas e/ou cantinas das instituições de ensino do município de Teixeira de Freitas (BA). Revista Baiana de Saúde Pública, 34(3):694-705.

Rompré, A., Servais, P., Baudart, J., De-Roubin, M. R., \& Laurent, P. (2002). Detection and enumeration of coliforms in drinking water: current methods and emerging. Journal of Microbiological Methods, 49:31-54.

Silva, L. J., Lopes, L. G., \& Amaral, L. A. (2016). Qualidade da água de abastecimento público do município de Jaboticabal, SP. Engenharia Sanitária e Ambiental, 21(3).

Souza, A. C. (2015). Consumo de água e de energia: uma análise sob a ótica do licenciamento ambiental na indústria de abate de animais do estado da Bahia. 2015. [Dissertação]. Universidade Estadual de Feira de Santana, Pós graduação em Engenharia Civil e Ambiental.

Wujie, J., Zhufei, M., \& Xujing, H. T. (2011). The influence of water quality on food quality and the treatment of water for food processing. Procedia Environmental Sciences, 1:2671-2676. 